ORIGINAL ARTICLE

\title{
CD44s is useful in the differentiation of benign and malignant papillary lesions of the breast
}

\author{
G M K Tse, P-H Tan, T K F Ma, C B Gilks, C S P Poon, B K B Law
}

J Clin Pathol 2005;58:1185-1188. doi: 10.1136/icp.2005.026906

See end of article for authors' affiliations

.....................

Correspondence to: Dr G M K Tse, Department of Anatomical and Cellular Pathology, Prince of Wales Hospital, Chinese

University of Hong Kong,

Ngan Shing Street, Shatin, NT, Hong Kong SAR; garyłse@cuhk.edu.hk

Accepted for publication 6 March 2005
Background/Aims: CD44s, the standard form of CD44, has been shown to be downregulated during malignant transformation of breast cancers. It has also been reported recently to be a useful marker in differentiating between benign and malignant papillary lesions of the breast, with high expression in the former. CD44s expression in benign and malignant papillary lesions was evaluated.

Methods: CD44s expression was assessed by immunohistochemistry in 101 benign papillomas and 59 papillary carcinomas (seven invasive papillary carcinomas, 41 papillary ductal carcinomas in situ, and 11 ductal carcinomas involving papillomas).

Results: Patients' age and tumour size were significantly different between the papilloma and papillary carcinoma groups $(p<0.0001)$. CD44s showed positive staining in 45 papillomas $(45 \%)$ and five papillary carcinomas ( $8 \%)$, and the difference was significant $(p<0.0001)$. The myoepithelial cells, when present, were also positive for CD44s in both groups, with no observable differences. Using CD44s positive staining to differentiate between benign and malignant papillary lesions gives a sensitivity, specificity, and accuracy of $45 \%, 92 \%$, and $62 \%$, respectively.

Conclusions: CD44s may be useful as an adjunct in the evaluation of morphologically problematic cases of papillary lesion of the breast.

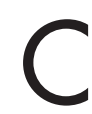

D44 is a family of transmembrane glycoproteins that have been implicated in cell-cell adhesion and cellmatrix adhesion, cell migration, and tumour metastasis. ${ }^{1-3}$ These molecules are also known to be involved in cell trafficking, lymphocyte homing, wound healing, and apoptosis..$^{4-7}$ In malignant diseases, such as ovarian cancer $^{89}$ and colorectal cancer, ${ }^{10}{ }^{11}$ aberrant expression has been shown to be associated with metastasis and worse prognosis. In breast cancers, CD44 expression had been shown to be downregulated during malignant transformation. ${ }^{12}$ Most previous studies on breast cancer concentrated on the prognostic implication of CD44 regulatory changes, ${ }^{13-16}$ with some authors demonstrating a correlation with hormonal receptor status. ${ }^{13}$

"Because morphological differentiation between benign and malignant mammary papillary lesions can be very difficult, the potential role of CD44 staining warrants further investigation"

A correlation with metastatic potential has been shown by some, ${ }^{17}$ but not others. ${ }^{16}$ Some investigators have also found that CD44 expression is more prominent in infiltrating lobular carcinoma than infiltrating ductal carcinoma, ${ }^{18}$ and that the expression varied between different histological groups of the lobular type. ${ }^{19}$ Recently, it has been reported that CD44 is a useful marker in differentiating between benign and malignant papillary lesions of the breast ${ }^{20}$ because the expression of CD44 was significantly higher in normal breast epithelium and intraduct papilloma than in papillary carcinoma. Because morphological differentiation between benign and malignant mammary papillary lesions can be very difficult, the potential role of CD44 staining warrants further investigation. In our study, a large series of papillary lesions of the breast collected from five institutions was assessed for CD44 protein expression by immunohistochemistry.

\section{MATERIALS AND METHODS}

The histopathology files of the involved institutions were searched for papillomas, intraduct papillomas, papillary carcinomas, and papillary ductal carcinomas in situ over a period of up to 12 years. All samples had been formalin fixed and routinely processed, and haematoxylin and eosin staining was performed on the $4 \mu \mathrm{m}$ thick sections. All the slides were retrieved and the haematoxylin and eosin slides were reviewed by two of the authors. The diagnosis was confirmed. Papilloma was diagnosed when the lesion showed an intraduct proliferation of epithelial cells showing an aborising pattern with well defined fibrovascular cores, and

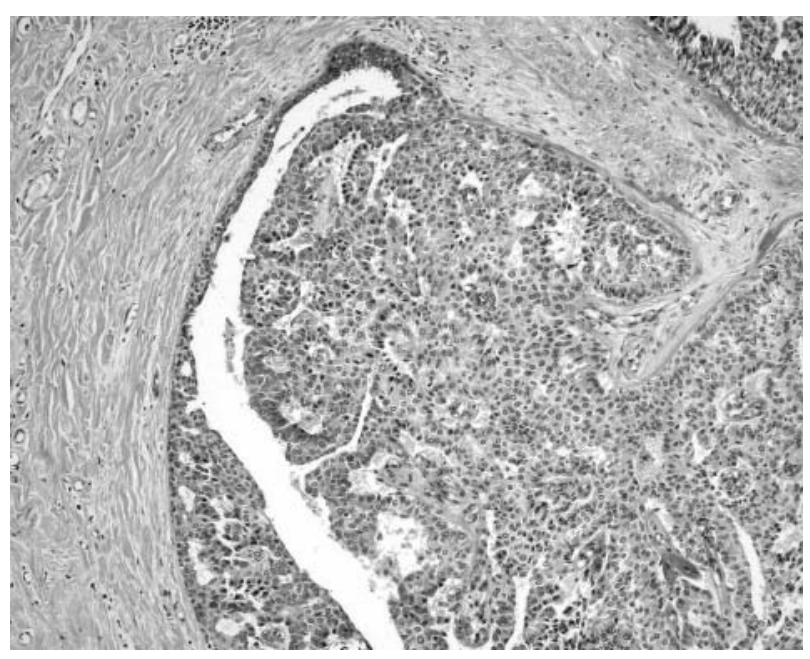

Figure 1 Photomicrograph showing part of a papilloma (haematoxylin and eosin staining; original magnification, $\times 100$ ).

Abbreviations: CD44s, standard isoform of CD44; CK, cytokeratin 
with an identifiable myoepithelial cell layer and minimal epithelial atypia. Papillary carcinomas were further subclassified as follows. (1) Invasive papillary carcinoma was diagnosed based on the presence of clusters of tumour cells penetrating the capsules of the tumours. (2) Papillary ductal carcinoma in situ was diagnosed based on the typical morphological features of papillary configuration with well defined fibrovascular cores, and the overlying neoplastic epithelium with cellular monotony, without underlying myoepithelial cells. (3) Ductal carcinoma in situ involving a papilloma was diagnosed based on the presence of confluent epithelial proliferation with features of solid or cribriform type ductal carcinoma in situ, but traversed by occasional broad bands of fibrous tissue containing fibrovascular structures. Lesions with epithelial hyperplasia showing features typical of atypical duct hyperplasia within a papilloma, and when the atypical focus measured more than $0.3 \mathrm{~cm}$, were also grouped into this category.

From each case of papillary carcinoma and papilloma, one representative section was selected for staining (CD44; $\mathrm{H}-$ CAM; clone F10-44-2, CD44s; 1/50 dilution; Novocastra Ltd, Newcastle upon Tyne, UK) using a modified avidin-biotin method with microwave antigen retrieval. All immunostaining was performed in one centre under the same conditions and was scored by one author. The staining of the epithelial cells was scored as strong, moderate, weak, or negative in intensity, using positive staining lymphocytes as the positive control for strong staining, when present. Only membranous staining was considered. The percentage of cells showing positive staining was also recorded. The lesion was considered positive for CD44 staining when there was moderate to strong staining in more than $10 \%$ of the epithelial cells.

The Student's $t$ test was used for comparing patients' age, lesion size, and immunostaining profiles between the two groups. Significance was established at $\mathrm{p}<0.05$.

\section{RESULTS}

In total, 160 lesions from 160 patients were identified, comprising 101 papillomas and 59 papillary carcinomas. All patients were female, with an age range of 22 to 89 years (mean, 52).

For the papillomas, the age range was $22-89$ years (mean, 48). The lesion size range was $0.1-2.2 \mathrm{~cm}$ (mean, 0.7). For the papillary carcinomas, the age range was 27-89 years (mean, 60). The lesion size range was $0.2-2.7 \mathrm{~cm}$ (mean, 1 ). The differences between patient age and lesion size, compar-

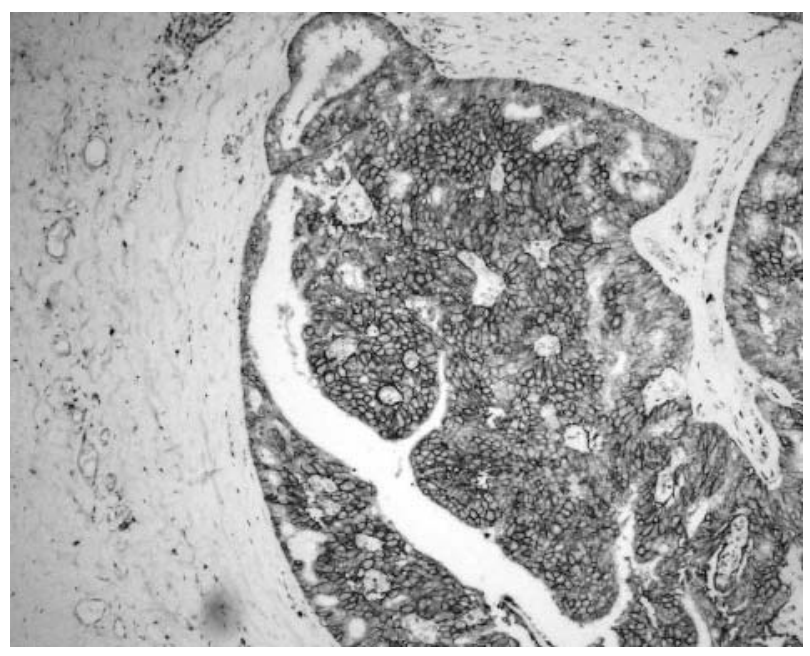

Figure 2 Photomicrograph of the same lesion showing positive staining for CD44. ing patients with papillomas with those with papillary carcinomas, were significant $(\mathrm{p}<0.0001)$.

Histological assessment of the papillomas revealed that 15 showed apocrine changes of the epithelium, 15 showed florid epithelial hyperplasia, and 10 showed sclerosis of the intervening stroma. These changes were focal within the papillomas. The cases of papillary carcinoma were divided into three groups, namely: invasive papillary carcinoma $(\mathrm{n}=7)$, papillary ductal carcinoma in situ $(\mathrm{n}=41)$, and ductal carcinoma in situ involving papillomas $(n=11)$. No lesions were found with atypical duct hyperplasia involving papillomas.

Immunostaining for CD44 was positive in 45 of the 101 papillomas $(45 \%)$ and in five of the 59 papillary carcinomas (figs 1, 2; table 1). The difference in CD44 staining between these two group was significant $(p<0.0001)$. The various subsets of papillary carcinoma (invasive papillary carcinomas, papillary ductal carcinoma in situ, and ductal carcinoma in situ involving papillomas) showed no differences in CD44 positivity. Myoepithelial cells in the background, when present, within and surrounding the lesions in the papillomas, and surrounding the distended ducts in papillary ductal carcinoma in situ and ductal carcinoma in situ involving papillomas, showed variable, moderate positivity in most cases. There were no differences between the various groups.

Using CD44 positive staining to differentiate between papilloma and papillary carcinoma, the sensitivity was $45 \%$ and specificity was $92 \%$, with a positive predictive value of $90 \%$ and a negative predictive value of $49 \%$. The accuracy was $62 \%$.

\section{DISCUSSION}

The diagnosis of carcinoma in situ within papillary lesions of the breast and the differentiation from papilloma is always fraught with difficulty. This is particularly problematical when the ductal carcinoma in situ involved is either low grade, or when it adopts a papillary configuration. In the absence of definite invasion, the morphological patterns can be similar. In the routine diagnostic investigation, immunohistochemical staining plays an important role in assisting such differentiation, utilising the fact that the cytokeratin (CK) expression spectrum is different between benign and malignant epithelium in malignant papillary lesions, ${ }^{21-27}$ and that myoepithelial cells are under-represented in malignant lesions, as highlighted by myoepithelial markers including actin, calponin, and p63. ${ }^{28}$ In general, immunohistochemistry to detect myoepithelial cells in problematic mammary papillary lesions has been widely used, but it has been shown that assessing the differential CK expression profiles (including CK5/6 and CK14) of the epithelial cells can also be useful. $^{29}$

CD44 has recently been reported to be useful in the assessment of papillary mammary lesions, with essentially positive epithelial staining seen in benign lesions, and negative staining in malignant lesions. ${ }^{20}$ In the current study, we were able to confirm this result in a much larger series of papillary lesions (160 lesions compared with 21 lesions), lending weight to the observation.

The role of CD44 in tumour pathology has been the subject of many investigations, particularly in tumour differentiation and metastasis. ${ }^{12}{ }^{17}$ Multiple functions have been attributed to different isoforms arising from pre-mRNA transcript or post-translational modification. ${ }^{2}$ Among these, the standard form CD44s lacks all variant exons and is widely expressed in lymphoid and non-lymphoid tissue, where it acts as a "homing" molecule. ${ }^{30}$ In breast carcinoma, CD44s mRNA expression had been shown to be significantly associated with disease free survival and overall survival. ${ }^{31}$ 
Table 1 Numbers of CD44 positive and negative cases among the different categories of papillary lesions

\begin{tabular}{llllr}
\hline Types & Subtypes & CD44 positive & CD44 negative & Total \\
\hline Papilloma & Papillary DCIS & $45(45 \%)$ & $56(55 \%)$ & 101 \\
Papillary carcinoma & DCIS involving papillomas & $3(7 \%)$ & $38(93 \%)$ & 41 \\
& Invasive papillary carcinoma & $1(9 \%)$ & $10(91 \%)$ & 11 \\
\hline DCIS, ductal carcinoma in situ. & & $1(17 \%)$ & $6(83 \%)$ & 7 \\
\hline
\end{tabular}

The expression of CD44s in the mammary epithelial cells of non-neoplastic, hyperplastic, and neoplastic lesions had also been studied. CD44s immunostaining was reported to be negative in normal breast ductal epithelium, but positive in the luminal epithelial cells of benign proliferative breast lesions, including papillomas, whereas in high grade ductal carcinoma in situ CD44s staining was lost. ${ }^{12}$

"Our series represents the largest reported so far in the literature, constituting 101 benign and 59 malignant papillary lesions"

CD44s expression in papillary lesions in the breast has not been well documented. CD44s expression had only been assessed in a few studies, totalling only six to 12 benign papillomas. ${ }^{12} 1820$ The results were variable, with two series showing positive staining of the epithelial cells, with luminal accentuation, ${ }^{12} 20$ whereas one study found no consistent staining pattern. ${ }^{18} \mathrm{CD} 44 \mathrm{~s}$ expression in papillary carcinomas, both in situ and invasive, is even less well characterised, with only one major series reporting a negative staining pattern. ${ }^{20}$ Our series represents the largest reported so far in the literature, constituting 101 benign and 59 malignant papillary lesions.

The mechanism of action of CD44 in tumour development and progression remains uncertain. Some data suggest that CD44 is associated with epidermal growth factor receptor and erbB2 oncogene expression in metastatic breast carcinoma, ${ }^{32}$ and that it potentiates the adherence of metastatic breast cancer cells to bone marrow endothelial cells. ${ }^{33}$ These factors may contribute to the observed association between CD44 expression and metastatic potential. The exact role of CD44 in papillary lesions of the breast remains unknown. One interesting observation is that in addition to the papillary epithelium being positive for CD44, the myoepithelial cells within the papillomas also showed positivity. Comparing the usual negative staining for normal breast epithelium ${ }^{12}$ with the positive staining in the papillomas suggests that the

\section{Take home messages}

- The immunohistochemical assessment of epithelial expression of the standard isoform of CD44 (CD44s) was useful in assisting the differentiation of benign from malignant lesions in a large series of papillary lesions of the breast

- CD44s may be useful as an adjunct in the evaluation of morphologically problematic cases of papillary lesion of the breast, particularly because it assesses the epithelial phenotypic difference between the groups of papillary lesions, complementing the usual panel that assesses the presence of myoepithelial cells

- The ability of CD44s to highlight the intralesional myoepithelial cells may further assist the differentiation of benign from malignant papillary lesions epithelial cells in papillomas show partial myoepithelial differentiation. Interestingly, a parallel observation of simultaneous expression of p63 (another established myoepithelial cell marker) in both epithelial and myoepithelial compartments of papillomas has also been reported. ${ }^{28}$ The validity and importance of this observation remain to be elucidated. It could be that CD44s is expressed by the epithelial cells showing basal and intermediate phenotypes, such as the cells found in papillomas, but not in papillary carcinomas, the cells of which have a more luminal phenotype.

In summary, we have shown that in a large series of papillary lesions of the breast, assessment of epithelial expression of CD44s by immunohistochemistry is useful in assisting the differentiation of benign from malignant lesions. CD44s is thus a promising candidate to be added to the repertoire of markers that are useful, particularly because it assesses the epithelial phenotypic difference between the groups of papillary lesions, complementing the usual panel that assesses the presence of myoepithelial cells. Furthermore, the ability of CD44s to highlight the intralesional myoepithelial cells may further assist the differentiation of benign from malignant papillary lesions.

\section{Authors' affiliations}

G M K Tse, Departments of Anatomical and Cellular Pathology, Prince of Wales Hospital, Chinese University of Hong Kong, Ngan Shing Street, Shatin, NT Hong Kong, SAR

P-H Tan, Department of Pathology, Singapore General Hospital, Singapore

T K F Ma, C S P Poon, Department of Pathology, North District Hospital, Hong Kong, SAR

C B Gilks, Department of Pathology, Vancouver General Hospital, Vancouver, BC V52 1M9, Canada

B K B Law, Breast Centre, Union Hospital, Hong Kong, SAR

\section{REFERENCES}

1 Price EA, Coombe DR, Murray JC. Endothelial CD44H mediates adhesion of a melanoma cell line to quiescent human endothelial cells in vitro. Int J Cancer 1996;65:513-18

2 Gunthert U. CD44: a multitude of isoforms with diverse functions. Curr Top Microbiol Immunol 1993;184:47-63.

3 Marhaba R, Zoller M. CD44 in cancer progression: adhesion, migration and growth regulation. J Mol Histol 2004;35:21 1-31.

4 Thomas L, Byers HR, Vink J, et al. CD44H regulates tumour cell migration on hyaluronate-coated substrate. J Cell Biol 1992;118:971-7.

5 Spicer AP, Roller ML, Camper SA, et al. The human and mouse receptors for hyaluronan-mediated motility, RHAMM, genes (HMMR) map to human chromosome 5q33.2-qter and mouse chromosome 11. Genomics 1995;30:115-17.

6 Ruiz P, Schwarzler C, Gunthert U. CD44 isoforms during differentiation and development. Bioessays 1995; 17:17-24.

7 Haynes BF, Liao HX, Patton KL. The transmembrane hyaluronate receptor (CD44): multiple functions, multiple forms. Cancer Cells 1991;3:347-50.

8 Bar JK, Grelewski P, Popiela A, et al. Type IV collagen and CD44v6 expression in benign, malignant primary and metastatic ovarian tumours: correlation with Ki-67 and p53 immunoreactivity. Gynecol Oncol 2004; $95: 23-31$

9 Zagorianakou N, Stefanou D, Makrydimas G, et al. CD44s expression, in benign, borderline and malignant tumours of ovarian surface epithelium. Correlation with p53, steroid receptor status, proliferative indices (PCNA, MIB1) and survival. Anticancer Res 2004;24:1665-70.

10 loachim E, Goussia A, Agnantis NJ. Glycoprotein CD44 expression in colorectal neoplasms. An immuno-histochemical study including correlation with cathepsin D, extracellular matrix components, p53, Rb, bcl-2, c-erbB-2, EGFR and proliferation indices. Virchows Arch 1999;434:45-50. 
11 Masaki T, Goto A, Sugiyama M, et al. Possible contribution of CD44 variant 6 and nuclear beta-catenin expression to the formation of budding tumour cells in patients with $\mathrm{T1}$ colorectal carcinoma. Cancer $2001 ; 92: 2539-46$.

12 Bankfalvi A, Terpe HJ, Breukelmann D, et al. Gains and losses of CD44 expression during breast carcinogenesis and tumour progression. Histopathology 1998;33:107-16.

13 Friedrichs K, Franke F, Lisboa BW, et al. CD44 isoforms correlate with cellula differentiation but not with prognosis in human breast cancer. Cancer Res 1995:55:5424-33.

14 Schumacher U, Horny HP, Horst HA, et al. A CD44 variant exon 6 epitope as a prognostic indicator in breast cancer. Eur J Surg Oncol 1996;22:259-61.

15 Guriec N, Marcellin L, Gairard B, et al. CD44 exon 6 expression as a possible early prognostic factor in primary node negative breast carcinoma. Clin Exp Metastasis 1996; 14:434-9

16 Regidor PA, Callies R, Regidor M, et al. Expression of the CD44 variant isoforms 6 and $4 / 5$ in breast cancer. Correlation with established prognostic parameters. Arch Gynecol Obstet 1996;258:125-35.

17 Rys J, Kruczak A, Lackowska B, et al. The role of CD44v3 expression in female breast carcinomas. Pol J Pathol 2003;54:243-7.

18 Krogerus LA, Leivonen M, Haasto AL. Expression patterns of biologic markers in small breast cancers and preneoplastic breast lesions. Breast 2000;9:281-5

19 Berner HS, Nesland JM. Expression of CD44 isoforms in infiltrating lobular carcinoma of the breast. Breast Cancer Res Treat 2001;65:23-9.

20 Saddik M, Lai R. CD44s as a surrogate marker for distinguishing intraductal papilloma from papillary carcinoma of the breast. J Clin Pathol 1999;52:862-4.

21 Bocker W, Bier B, Freytag G, et al. An immunohistochemical study of the breast using antibodies to basal and luminal keratins, alpha-smooth muscle actin, vimentin, collagen IV and laminin. Part I: normal breast and benign proliferative lesions. Virchows Arch A Pathol Anat Histopathol 1992:421:315-22.

22 Bocker W, Bier B, Freytag G, et al. An immunohistochemical study of the breast using antibodies to basal and luminal keratins, alpha-smooth muscle actin, vimentin, collagen IV and laminin. Part II: epitheliosis and ductal carcinoma in situ. Virchows Arch A Pathol Anat Histopathol 1992;421:323-30

23 Boecker W, Buerger H, Schmitz K, et al. Ductal epithelial proliferations of the breast: a biological continuum? Comparative genomic hybridization and high molecular-weight cytokeratin expression patterns. J Pathol 2001;195:415-21.

24 Jarasch ED, Nagle RB, Kaufmann M, et al. Differential diagnosis of benign epithelial proliferations and carcinomas of the breast using antibodies to cytokeratins. Hum Pathol 1988;19:276-89.

25 Lacroix-Triki M, Mery E, Voigt JJ, et al. Value of cytokeratin 5/6 immunostaining using D5/16 B4 antibody in the spectrum of proliferative intraepithelial lesions of the breast. A comparative study with 34 betaE12 antibody. Virchows Arch 2003;442:548-54

26 Otterbach F, Bankfalvi A, Bergner S. Cytokeratin 5/6 immunohistochemistry assists the differential diagnosis of atypical proliferations of the breast. Histopathology 2000;37:232-40

27 Raju U, Crissman JD, Zarbo RJ, et al. Epitheliosis of the breast. An immunohistochemical characterization and comparison to malignant intraductal proliferations of the breast. Am J Surg Pathol 1990;14:939-47.

28 Stefanou D, Batistatou A, Nonni A, et al. p63 expression in benign and malignant breast lesions. Histol Histopathol 2004; 19:465-71.

29 Tan PH, Aw MY, Yip G, et al. Cytokeratins in papillary lesions of the breast: is there a role in distinguishing intraductal papilloma from papillary ductal carcinoma in situ? Am J Surg Pathol 2005:29:625-32.

30 Sinn HP, Heider KH, Skroch-Angel P, et al. Human mammary carcinomas express homologues of rat metastasis-associated variants of CD44. Breast Cancer Res Treat 1995;36:307-13.

31 Berner HS, Suo Z, Risberg B, et al. Clinicopathological associations of CD44 mRNA and protein expression in primary breast carcinomas. Histopathology 2003;42:546-54

32 Wobus M, Rangwala R, Sheyn I, et al. CD44 associates with EGFR and erbB2 in metastasizing mammary carcinoma cells. Appl Immunohistochem Mol Morphol 2002;10:34-9.

33 Draffin JE, McFarlane S, Hill A, et al. CD44 potentiates the adherence of metastatic prostate and breast cancer cells to bone marrow endothelial cells. Cancer Res 2004;64:5702-11

\section{bmjupdates+}

bmjupdates+ is a unique and free alerting service, designed to keep you up to date with the medical literature that is truly important to your practice.

bmjupdates+ will alert you to important new research and will provide you with the best new evidence concerning important advances in health care, tailored to your medical interests and time demands.

Where does the information come from?

bmjupdates+ applies an expert critical appraisal filter to over 100 top medical journals A panel of over 2000 physicians find the few 'must read' studies for each area of clinical interest

Sign up to receive your tailored email alerts, searching access and more...

www.bmjupdates.com 